\title{
LA AGENDA 2030: \\ ¿CAMBIAR EL MUNDO \\ SIN CAMBIAR LA DISTRIBUCIÓN DEL PODER?
}

\author{
Pablo José Martínez Osés
}

Ignacio MarTínez MarTíneZ

DOI: $10.1387 /$ lan-harremanak.16094

\section{ABSTRACT}

El artículo explora las posibilidades y limites que la Agenda 2030 presenta para ser una agenda transformadora. Mediante un análisis critico de los procesos de su construcción se observan contradicciones, límites y dilemas que la Agenda 2030 no podrá eludir. En un contexto global de cambios en la distribución del poder internacional se sugiere considerar la Agenda 2030 como un proceso inacabado, como un espacio en disputa, pendiente de interpretaciones politicas desde diferentes actores. Construir la narrativa sobre desarrollo humano desde una perspectiva integral, universal y democrática exigirá considerar la nueva Agenda como un proceso abierto y dinámico, como una agenda de agregados más que como un consenso cerrado y suficiente, solo pendiente de implementación. El espacio politico de la sociedad civil global es precisamente contribuir a una narrativa sobre la Agenda 2030 compatible con los derechos humanos y con el abordaje de cuestiones sistémicas nucleares para las transformaciones pretendidas.

Palabras clave: Agenda 2030, participación política, poder, coherencia de politicas.

The article explores the possibilities and limits of Agenda 2030 as an agenda for change. Through critical analysis of its constructions it notes contradictions, limits and dilemmas that Agenda 2030 cannot escape. In a global context of changes in 
the distribution of international power, it is suggested that Agenda 2030 should be considered as an unfinished process, as a contested space, awaiting political interpretations by different players. Building a narrative about human development from a holistic, universal and democratic standpoint must involve considering the new Agenda as an open, dynamic process, as an agenda of aggregates rather than a closed, sufficient consensus, simply pending implementation. The political space of global civil society is precisely to contribute to a narrative about Agenda 2030 that is compatible with human rights and to approaching core systemic issues for the transformations aimed at.

Keywords: Agenda 2030, political participation, power, coherence of policies.

Artikulu honek 2.030 Agendak benetako agenda eraldatzailea izateko dituen aukerak eta mugak ikertzen ditu. Agendaren eraiketa prozesuaren analisi kritiko baten bidez ekidin ezineko kontraesan, muga eta dilemak ikusten ditugu. Nazioarteko botere banaketaren aldaketa ezaugarritzat duen testu ingurune honetan, Agenda 2030 bukatu gabeko prozesu bezala ulertzea proposatzen dugu, lehian dagoen eremu bezala, eta eragile desberdinen interpretazioaren faltan dagoena. Giza garapenaren gaineko narratiba ikuspegi integral, unibertsal eta demokratiko batetik egiteak eskatzen du Agenda berria prozesu ireki eta dinamiko gisa ulertzea, agregatutakoen agenda bezala, eta ez horrenbeste indarrean jartzea besterik falta ez zaion kontsentsu itxi eta aski bat legez. Gizarte zibil globalaren gune politikoa narratiba baten alde egitean datza, hain zuzen, giza eskubideekin eta lortu nahi diren eraldaketak gauzatu ahal izateko gako sistemikoen abordatzearekin ados datorren narratiba baten alde.

Hitz gakoak: 2030 Agenda, partaidetza politikoa, boterea, politiken koherentzia. 


\section{Introducción: la desconexión entre la agenda internacional y el debate sobre el desarrollo}

Desde que iniciara el debate moderno sobre el desarrollo en la segunda mitad del siglo xx este ha sido, como tantos otros, un espacio de disputa teórica. Numerosas aproximaciones a la noción de desarrollo, diferentes teorías construidas desde cada vez más disciplinas han ido conformando y ampliando el debate y extendiendo la denominada doctrina sobre desarrollo. Resultado de esa lógica de construcción de conocimiento desde la confrontación de ideas, complementariedad y evolución de enfoques y creciente número de miradas, contamos en la actualidad con un cuerpo doctrinal amplio y complejo, en el que conviven numerosas visiones sobre el desarrollo, muchas de ellas divergentes e incluso, opuestas o antagonistas en su manera de entender dicho concepto (Cornago, 1997; Unceta, 2014).

Dentro de la enorme heterogeneidad de maneras de entender y teorizar sobre el desarrollo parece claro que ha habido un desplazamiento del núcleo del debate que ha permitido evolucionar desde miradas unidimensionales que asimilaban la idea de desarrollo con la existencia de bienestar material y de capacidad productiva (Alonso, 2006: 2) y, por lo tanto, centrado en el crecimiento económico (Bustelo, 1998: 118), hacia miradas más amplias que tratan de recoger la complejidad de esta noción y reconocer las diferentes dimensiones y concepciones del bienestar sobre las que se construye (Sen, 2000; Alonso, 2006; Unceta, 2009). De hecho, el propio debate sobre el desarrollo ha superado los límites de la noción del desarrollo, incorporando cada vez más voces, no solo desde la academia sino, principalmente, desde la sociedad civil y, también de manera creciente, desde la práctica política que ponen en cuestionamiento la idea de progreso en la que se asienta la noción de desarrollo (Fernández, Piris, y Ramiro, 2013; Unceta, 2014; Delgado, 2014). Así pues, sin poder hablar de un amplio consenso teórico sobre la noción de desarrollo, sí puede identificarse con claridad la consolidación de un paradigma que concibe el desarrollo desde una lógica multidimensional que, en la actualidad, se encarna en la noción de desarrollo humano y sostenible.

Paralelamente, a lo largo de estas décadas del debate sobre el desarrollo se observa de manera constante cómo los avances en el terreno del debate teórico son a menudo incorporados en el discurso político pero encuentran enormes dificultades para concretarse en la práctica política y en los sistemas públicos de 
tomas de decisiones, que a lo largo de décadas se han mostrado incapaces de dar respuesta a los problemas del desarrollo. De hecho, más bien parece que hubiera ocurrido que a medida que la noción de desarrollo se hacía más compleja y ambiciosa desde la lógica que se concebía, más se ha alejado la práctica política del debate teórico, y más se agravaban los mencionados problemas. Este mismo problema, la dificultad del conocimiento y los enfoques con mayor capacidad de reconocer la complejidad de los problemas del desarrollo para influir en la toma de decisiones políticas, se ha producido incluso en torno a la agenda política específica del desarrollo, especialmente a medida que se iba concretando en un compromiso colectivo con opciones de generar responsabilidades entre los diferentes actores de la sociedad internacional. Así, la Agenda del Milenio y los resultantes Objetivos de Desarrollo del Milenio (ODM) supusieron una buena muestra de cómo un intento de trasladar parte de la doctrina sobre desarrollo al terreno de la política acabó resultando en una propuesta que se alejó de manera significativa de lo que el relativo consenso en la doctrina sobre el desarrollo hubiera sugerido. En resumidas cuentas, el enfoque teórico dominante acumulado en los debates sobre el desarrollo hacia el final del siglo xx no permeó en el consenso político alcanzado a través de los ODM (Martínez Osés, 2005).

Lo cierto es que mientras que la parte más declarativa de la Agenda del Milenio - la Declaración del Milenio - sí puede considerarse como un adecuado diagnóstico y punto de partida desde el punto de vista del enfoque de desarrollo humano, su mandato político — los objetivos, las metas y los indicadoressignificaron una interpretación muy diferente y no estuvieron a la altura del conocimiento acumulado y expresado en los debates sobre desarrollo (Martínez Osés, 2005; Sanahuja, 2007; Tezanos, 2011; Bissio, 2011). Es más relevante esta cuestión cuando parecía que a lo largo de la década de los noventa del pasado siglo el consenso sobre la doctrina del desarrollo se había ido construyendo a partir de la imbricación de los debates teóricos sobre el desarrollo, el activismo y la movilización social y los avances en el marco institucional multilateral, de manera especial en el seno de Naciones Unidas (NNUU), reflejados en las cumbres y conferencias internacionales que fueron configurando una ambiciosa agenda de desarrollo (Martínez Osés, 2005).

Sin negar la existencia de impactos y efectos positivos resultado de la Agenda del Milenio, parecen existir razonables cuestionamientos en relación a la capacidad que han tenido para contribuir al desarrollo, tanto en términos cuantitativos como en su efecto prescriptor de políticas a favor del desarrollo ${ }^{1}$. Coincidiendo

1 Desde que se acordaran estos objetivos hace ya tres lustros, numerosos han sido los análisis que han tratado sobre el origen y la naturaleza de esta agenda (Alonso, 2013; Cheru y Bradford Jr, 2005; Martínez Osés, 2005; Tezanos, 2011; Vandemoortele, 2002), sobre sus fortalezas y limitaciones (Martínez Osés, 2005; Sanahuja, 2007) y sobre su grado de cumplimiento (Plataforma 2015 y más, 2004, 2005, 2006, 2008a, 2008b, 2009; 2011a, 2012, 2013 y 2014). 
con el periodo de vigencia de los ODM se han producido otras dinámicas que parecen haber sido más determinantes para algunos de los resultados atribuidos al impacto de los ODM. Tal es el caso del crecimiento económico de los denominados países emergentes, muy especialmente de China, en relación a la evolución del número de personas en situación de pobreza extrema (Sanahuja, 2013), o la Guerra Global contra el Terror, iniciada por Estados Unidos tras los atentados de Nueva York el 11 de Septiembre de 2011, que pudo tener un efecto movilizador de Ayuda Oficial al Desarrollo (AOD) al calor de la securitización de la agenda de desarrollo (Sanahuja, 2005) más relevante que los propios ODM. Se trata no obstante de dinámicas que, al tiempo que podían contribuir al cumplimiento de los ODM, profundizaban en la generación de otros problemas del desarrollo de carácter estructural relacionados con el deterioro ambiental, el aumento de las desigualdades o la inseguridad humana.

Las lecciones que de este periodo pueden extraerse son de gran utilidad para entender y contextualizar el momento actual y el futuro de la Agenda 2030 aprobada en la Asamblea General de las Naciones Unidas en septiembre de 2015, sucesora de la Agenda del Milenio. En primer lugar, la conformación de la agenda de desarrollo responde más a un terreno de disputa política y defensa de visiones e intereses de aquellos actores que la conforman y definen. El resultado, por lo tanto, tiene mayor relación con la distribución del poder de los actores que participan en su proceso de construcción que con la capacidad del proceso de articular una respuesta a los problemas del desarrollo desde una posición informada a partir del debate sobre el desarrollo. Ello, independientemente de que los partícipes del proceso asuman discursivamente los posibles consensos resultantes de los debates del desarrollo.

En segundo lugar, la agenda internacional de desarrollo no constituye el único marco de referencia, ni siquiera el más relevante, en el que se toman las principales decisiones que afectan a los problemas centrales del desarrollo como la desigualdad, el cambio climático, la seguridad humana o los derechos humanos. Las negociaciones comerciales, los acuerdos de inversión, la agenda sobre fiscalidad, el derecho internacional, por mencionar solo algunos de los más relevantes ámbitos para la gobernanza global, no han formado parte - salvo en algún caso de manera tangencial, confusa o contradictoria-, de la Agenda 2030. Sin negar que esta agenda, a diferencia de su predecesora Agenda del Milenio, ha abordado cuestiones de gobernanza e incluso recoge algunos elementos que podrían denominarse sistémicos, no alcanza a penetrar con capacidad efectiva en los ámbitos de gobernanza de mayor relevancia para hacer frente a los problemas del desarrollo.

Sin embargo, en contraste de lo que parece ir imponiéndose como narrativa inicial, no estamos ante una agenda finalizada. Nos encontramos ante un proceso inacabado que es necesario interpretar, adoptar e implementar desde 
los diferentes países y entre los diferentes actores sociales y políticos. Parece por lo tanto que, como la propia noción de desarrollo, la narrativa en torno a esta agenda y el desarrollo de esta se encuentra todavía en disputa y construcción. Es esta la tarea que la denominada comunidad del desarrollo tiene ahora por delante en numerosos contextos.

Son estas reflexiones las que se desarrollan en los siguientes epígrafes de este artículo. El segundo epígrafe se dedica a analizar el proceso de construcción de la inicialmente denominada agenda post-2015, identificando los límites del proceso y cómo estos límites, que son a su vez un reflejo de los límites que la realidad internacional muestra en materia de gobernanza democrática y multinivel, se sitúan en la base de los resultados alcanzados en la definición final de la agenda. En el tercer apartado se plantea que, frente a un escenario de implementación de un proceso de definición de la agenda ya acabado, emerge la responsabilidad de construir la apertura de un espacio para reconfigurar y resignificar la agenda, en línea con la doctrina o los debates sobre el desarrollo y a partir de la mirada específica de los diferentes actores sociales y políticos de los diferentes contextos. De ello dependerá, en buena medida, el potencial de transformación y cambio estructural para un mejor modelo de gobernanza global, democrática y multinivel. Por último, el artículo finaliza con unas reflexiones finales sobre los límites de la agenda y su capacidad de dar respuesta a problemas transnacionales enmarcados en constantes procesos de transformación.

\section{Análisis crítico de la Agenda 2030}

Un análisis detenido de la Agenda 2030 no debe limitarse a considerar esta como un acuerdo acabado y cerrado. Por un lado es preciso en primer lugar atender a los aprendizajes derivados del complejo proceso de construcción que ha sido liderado por NNUU durante los tres últimos años en la medida en que nos permitirán comprender mejor el enfoque y el alcance del acuerdo final. Por otro lado la Agenda 2030 debe considerarse como un punto de partida para la discusión de muchos asuntos, más que como un consenso cerrado y completo, y que por lo tanto no debiera seguir evolucionando en los próximos años. Una de claves para comprender cabalmente qué significará la Agenda 2030 nos la proporcionará, precisamente, el análisis de su evolución durante los próximos quince años.

\subsection{Análisis a partir de los procesos de construcción de la Agenda 2030}

En otro lugar ya se han realizado detalladas descripciones de las diferentes iniciativas que se han puesto en marcha institucionalmente, en particular desde septiembre de 2012 y que, en mayor o menor medida, han estado vinculadas o 
han influido en el resultado final de la Agenda 2030 (United Nations, 2015a). Es un error demasiado común, y también demasiado aceptado, considerar que el proceso de construcción ha estado planificado y guiado racionalmente desde el principio a partir de un diseño predeterminado. Parece más ajustado a la realidad observarlo como un periodo de amplias discusiones y tensiones entre múltiples actores con notables diferencias entre ellos, entre sus respectivos intereses y objetivos, y entre sus respectivas capacidades para alcanzarlos. Es necesaria esta perspectiva para comprender mejor cómo funcionan los dinamismos de la realidad y evitar imponer una interpretación simplista y equívoca sobre su construcción. Se ha tratado de un periodo durante el que no se ha dispuesto de una clara "hoja de ruta», ni de un transparente sistema de toma de decisiones sobre los asuntos cruciales, por más que el sistema organizativo de las NNUU exigiera que la forma al final del proceso tuviera que tener el clásico acuerdo de carácter intergubernamental adoptado en la Asamblea General de NNUU a finales del pasado mes de septiembre.

\section{a) Concepción ilusa de la participación ciudadana como acceso a las consultas}

No parece arriesgado afirmar que el proceso de definición de la nueva agenda internacional de desarrollo ha sido un periodo en el que ha primado la búsqueda de legitimidad mediante continuos canales de consultas simultáneos $y$, a veces, entrecruzados. No en vano, el mundo en 2015 es muy diferente al mundo del 2000, en el que unas pocas élites tecnócratas de los países donantes pudieron imponer unos ODM a la Comunidad Internacional (Alonso, 2013: 100). El avance y la extensión de las Tecnologías de la Comunicación y de la Información (TIC), no solo ampliaron el acceso a las mismas a más personas en todas las latitudes, sino que este ha sido una influencia decisiva en procesos de movilización social y política que en multitud de países visibilizaron su desconfianza de las élites y la insuficiencia de los sistemas políticos de representación clásicos. Por lo tanto, en busca de aunar mayor legitimidad se han hecho enormes esfuerzos institucionales por abrir canales de consulta, en los que diferentes personas de diversas procedencias pudieran exponer sus diagnósticos de los principales desafíos y sus expectativas y propuestas respecto a las posibles soluciones (Martínez Osés, 2015).

Sin embargo, conviene no confundir el acceso a dichas consultas o la posibilidad de responder individualmente a una encuesta sobre prioridades preestablecidas por Internet con genuinos procesos de participación ciudadana en la definición de estrategias políticas globales. Para aproximarse a una comprensión de la Agenda 2030 en términos de elaboración colectiva, es preciso realizar un análisis cualitativo de la influencia de los diferentes actores, en lugar de limitarse a afirmar que participaron tantos cientos de representantes de organizaciones sociales, empresariales y tantos otros representantes de gobiernos, o tantos millones de encuestas enviadas utilizando Internet. Afirmar que la Agenda 2030 es 
una propuesta elaborada de forma participativa, con la participación activa de la ciudadanía basada en aquellas cifras, es conformarse con una concepción de la participación política apenas decorativa y legitimadora de acuerdos preestablecidos o por definir. Afirmar, como se hace en el propio texto de la declaración oficial, que es una Agenda "del pueblo y para el pueblo» (United Nations, 2015b: párr. 52) es tratar de ocultar la brecha que existe tanto, entre los intereses de los pueblos y los de las élites, como entre la capacidad efectiva que existe entre unos y otros de influir y configurar los acuerdos globales.

\section{b) Distribución y difusión del poder internacional}

La Agenda 2030 es un reflejo de la distribución del poder internacional, en particular de cómo el denominado poder estructural se ha dispersado y difuminado entre diversos actores, respondiendo cada vez más a una lógica transnacional que a la antigua consideración de la sociedad internacional como el producto de las relaciones de poder entre los diferentes Estados (Strange, 1994; Cox, 1996; Lawton, Rosenau, y Verdun 2000; Strange, 2001). En palabras de Strange, el poder estructural es aquel que configura y determina las estructuras de la economía política global en las que los Estados, sus instituciones políticas, sus empresas, sus científicos y gente de otras profesiones tienen que operar. Es mucho más importante que el poder relacional de un Estado sobre otro, y aboca a una concepción más amplia de la tradicional división entre el poder económico y el poder político. Un análisis de la Agenda 2030 debe, por lo tanto, recoger la principal evidencia de los análisis de Strange, a partir de la cual para comprender la sociedad internacional el análisis no podía seguir reduciéndose a lo que hacen los Estados, sino que debían incorporar también la fuerza y el poder con que otros actores contribuyen a configurar la sociedad internacional, particularmente las compañías privadas y en su formulación más genérica, las fuerzas del mercado.

Esta distribución del poder internacional no puede comprenderse como un mero desplazamiento del poder antaño en manos de los Estados a las de las Empresas Transnacionales (ETN). Más bien ha supuesto una difusión del poder, que ha pasado de explicarse a partir de lógicas de representación territorial en clave de soberanía a configurarse como complejas matrices de intereses transnacionalizados. No solo el denominado sector privado, propietario principal del capital, se ha transnacionalizado; también los Estados enfrentan desafíos y atienden demandas de carácter transnacional cuyo vínculo con los intereses de sus ciudadanos no es siempre claro ni preciso; y también las Organizaciones de la Sociedad Civil (OSC) han evolucionado en las últimas décadas tratando, de una manera $\mathrm{u}$ otra, de construir posiciones y narrativas sobre los intereses transnacionales de las poblaciones vulnerables y sistemáticamente excluidas del denominado proceso de globalización. Cada vez es más complejo encontrar posturas que nieguen que los problemas fundamentales como el cambio climático, las 
políticas de producción y de redistribución, la deuda pública y el déficit fiscal o la lucha contra la desigualdad y la extensión de los Derechos Humanos difícilmente puedan resolverse desde las capacidades propias de los Estados. El ejercicio tradicional de la política de los Estados queda prácticamente reducido a la retórica si no se consideran los espacios y las fuerzas que dirigen y explican el actual proceso de transnacionalización de intereses. Así, sería una ingenuidad que nos alejaría de una compresión cabal, pensar que tanto en la configuración de la Agenda 2030 como en las posibilidades de implementación de lo que en ella se establece, baste con apelar a la voluntad política de los gobiernos de los Estados.

Este cambio aquí brevemente descrito se refleja con una creciente intensidad en el ámbito propio del desarrollo en la última década, a medida que se ha convertido en lugar común la aparición del denominado sector privado, tanto en su consideración como nuevo actor de desarrollo como en las reiteradas peticiones y apuestas porque los flujos económicos de su procedencia y responsabilidad pasen a formar parte, o a ser considerados, como flujos netos para el desarrollo. La Declaración de Busan (2011), la actual ampliación del concepto de AOD al ya denominado Total Official Support for Sustainable Development (TOSSD) (OECD-CAD 2014), la creciente visibilidad del denominado filantrocapitalismo global o la evolución de los trabajos de la iniciativa Global Compact, entre otras, en NNUU ponen de manifiesto la creciente importancia que se le atribuye al sector privado transnacional en la configuración y en las prácticas del desarrollo (Adams y Martens, 2015).

Particularmente en los procesos de construcción de la Agenda 2030 su presencia ha sido notablemente influyente. No solo financiando directamente a la oficina responsable de la articulación del conjunto de procesos, dirigida por Amina Mohamed como hicieron las fundaciones de Ted Turner y de Bill y Melinda Gates (Pingeot, 2014: 20), o financiando la Red de Soluciones para el Desarrollo Sostenible (RSDS) sino participando directamente en la configuración de cada paso del proceso. La influencia del sector privado transnacional en estos procesos de construcción ha sido evidente durante todo el periodo, en el que han tenido una presencia constante en las discusiones, debates y elaboración de propuestas. También algunas organizaciones o plataformas sociales han tratado de seguir muy de cerca y participar en los espacios accesibles para ello. Esto no quiere decir, como suele afirmarse, que unos y otros hayan participado de forma sistemática y en clave de igualdad de acceso a los debates para la construcción de la Agenda, como si de diferentes grupos de «interesados» (multistakeholders es el celebérrimo término en inglés) se tratara.

$\mathrm{Al}$ contrario, es preciso atender a lo que José $\mathrm{Medina}^{2}$ ha denominado la «estructura de escucha» para significar las diferentes capacidades que los diversos ac-

\footnotetext{
${ }^{2}$ Esta idea ha sido expuesta por José Medina en varias conferencias e intervenciones públicas.
} 
tores tienen para atraer el interés y en consecuencia ver cómo sus propuestas son sentidas como más adecuadas y aceptadas para ser introducidas. Ha sido enormemente difícil para las plataformas de las organizaciones sociales contar con representantes de alto nivel de las NNUU en sus eventos y debates, mientras que a la misma hora y en una sala solo a pocos metros de aquella, podían encontrarse a multitud de representantes institucionales tanto de NNUU como de los gobiernos atendiendo a las propuestas de alguna compańía transnacional de la energía, de la alimentación o de la industria farmacéutica. Sin duda que la diferencia no estribaba en el interés ni en el rigor de las propuestas o debates que se daban en una sala y otra. La diferencia radica, fundamentalmente, en la distinta capacidad material para organizar eventos y la influencia que esta tiene en la proyección institucional, así como en la diferente capacidad de influencias y establecimiento de contactos en los ámbitos de concentración del poder de unos y otros grupos. Como también dista la capacidad de realizar y publicar ideas y propuestas a través de los medios de comunicación y de la publicidad de unos y otros. Todo ello pone de manifiesto que el fenómeno de la estructura de escucha, lejos de ser ocasional y aplicado a este proceso de construcción, es un fenómeno estructural y que, por su propia dinámica, tiende a reproducirse.

Ni siquiera logran superar las limitaciones de esa estructura de escucha cuando más de 3.000 organizaciones de base de todo el mundo a través de 120 redes y plataformas de organizaciones sociales, consensúan un documento de recomendaciones para que la nueva Agenda 2030 sea verdaderamente transformadora en materia de equidad, sostenibilidad y derechos (UN-NGSL, 2013). Ni siquiera aunque dicho proceso de consultas y debates lo hagan a través de la oficina oficial de enlace de la Sociedad Civil con el Secretario General de las NNUU y presenten el informe ante las Comisiones Regionales de NNUU al mismo Presidente de la Asamblea General, consiguen que estas recomendaciones sean tenidas en cuenta en el informe de síntesis del proceso que el Secretario General publica y constituye los límites de lo que se puede y no se puede considerar para la discusión final sobre la Agenda (UN-SG, 2014).

\section{c) La Agenda 2030 como un agregado de demandas transnacionales}

Tanto el acceso a las diversas consultas como el resto de la actividad desplegada mediante múltiples medios por las redes de organizaciones sociales han tenido mayor influencia en la Agenda 2030 desde el punto de vista del diagnóstico que esta recoge que desde la definición final de metas y medios para resolver los desafíos. Es apreciable que durante el proceso de construcción de la nueva agenda, algunas cuestiones que finalmente han sido consideradas y contempladas han tenido enormes dificultades y evidentes oposiciones para lograr ser incluidas. La cuestión de la desigualdad de renta, la incorporación del desafío ambiental y su vínculo estrecho con el modelo de desarrollo, la economía de los cuidados, o las necesidades especiales de los pequeños productores de alimen- 
tos en condiciones ecológicamente sostenibles han sido finalmente mencionados en algún lugar de la declaración. También la amplitud de temas que aborda la Agenda 2030 ha sido objeto de discusión, logrando finalmente que la misma tuviera el carácter holístico que requieren los complejos desafíos del desarrollo global mostrando, en alguna medida, las interdependencias entre los espacios económicos, ecológicos, sociales y políticos a los que una concepción del desarrollo multidimensional obliga. Esta amplitud de temas, que cristaliza en 17 objetivos y 169 metas ha sido recurrentemente denostada desde argumentos de marcado carácter tecnocrático que invitaban a una agenda mucho más focalizada por razones de comunicación pública y pretendida eficacia en su implementación.

Todo lo anterior no quiere decir que las cuestiones mencionadas o la amplitud e integralidad de la Agenda 2030 puedan ser consideradas materias prioritarias adoptadas por parte de los gobiernos y resto de actores implicados. La Agenda 2030 contiene notables contradicciones y presenta incoherencias serias en relación al modelo de desarrollo que promueve en su conjunto. Destacan sobremanera el peso específico que se le otorga al crecimiento económico como motor principal del desarrollo, obviando o contradiciendo el arraigo social, ecológico y político de la economía; la imposibilidad de incorporar medidas legalmente vinculantes y un sistema de sanciones a los incumplidores; o que todos los denominados asuntos sistémicos, como la regulación de mercados financieros, los mecanismos fiscales internacionales, la reorientación de los mecanismos de negociación y desregulación comercial o la evaluación y gestión multilateral de la problemática derivada de la deuda externa no hayan logrado concretar ninguna medida específica entre los nuevos objetivos de desarrollo. Así, el pretendido carácter transformador de la Agenda 2030 queda completamente en entredicho. Ni transición hacia modelos más sostenibles, ni mayor y más democrática gobernanza global sobre asuntos comunes, ni un marco apropiado para afrontar de forma corresponsable los grandes desafíos quedan recogidos en ella. Una única mención a las «responsabilidades comunes pero diferenciadas» (United Nations, 2015b: párr. 12) al principio, entre los párrafos más declarativos e introductorios, sin ninguna concreción específica entre las 169 metas acordadas ni entre los llamados medios de implementación, sobre las responsabilidades que los diferentes Estados deben adoptar; parece insuficiente y mal augurio como para hacer descansar muchas esperanzas de transformación en el texto final acordado.

De esta forma debería rechazarse la idea de la Agenda 2030 como un consenso entre todas las partes implicadas. Se trata más bien de un agregado de temas y cuestiones que responden a menudo a intereses contrapuestos. El rastro del carácter supuestamente intergubernamental del proceso es difícil de encontrar, puesto que prevalecen los intereses de carácter transnacional sobre los recursos naturales, los privilegios del sector privado transnacional respecto de gobiernos y «sus» poblaciones vulnerables. El documento final combina una alta carga de ideas y valores declarativos que fulgen como normativos con una esca- 
sez de medidas vinculantes para ninguno de los actores. El enfoque basado en los derechos humanos y la consiguiente propuesta de desarrollar los mecanismos para hacer cumplir las obligaciones que en esa materia tienen los Estados, las empresas y los ciudadanos ha sido rechazado como enfoque para el mundo que queremos en el ańo 2030. A cambio, disponemos de un amplio y a veces detallado conjunto de transformaciones que queremos alcanzar, sin detallar quiénes tienen las responsabilidades principales de hacerlo y cómo han de asumirlas. Para tamańo desafío parece ingenuo pensar que los llamamientos a la corresponsabilidad y al compromiso serán del todo suficientes.

Considerar la Agenda 2030 como un consenso puede constituir una trampa tal y como Stephen Gill denominó al «nuevo constitucionalismo» que contribuye a mantener el proceso de globalización como un proceso de dominación de intereses de clases transnacionales sobre el resto de los seres humanos (Gill, 1995; Gill, 2008). ¿Cómo es posible que consideremos la Agenda 2030 como un consenso que integra los intereses de las organizaciones sociales cuando ha rehuido acuerdos vinculantes y es ambivalente respecto de los medios y responsabilidades para lograr las transformaciones? La Agenda 2030 es probablemente la mejor agenda de la que podíamos disponer teniendo en cuenta las fuerzas y poderes que configuran la marcha de nuestro mundo en la actualidad. Pero al mismo tiempo, muestra desde su mismo proceso de construcción sus límites obscenos en una distribución y una difusión del poder internacional que difícilmente puede garantizar un tránsito hacia un mundo equitativo, habitable y seguro para las generaciones venideras. Y nada, en dicha Agenda, parece decidido a transformar ni a reorientar la actual distribución del poder global.

\subsection{Análisis de principales resultados en la Agenda 2030}

Lo cierto es que después de un largo periodo disponemos de una nueva Agenda 2030 aprobada por la Asamblea General de las NNUU. Y en tanto que resultado de la capacidad de debate y diálogo de un mundo que evidencia mayores interdependencias e interconexiones, con una estructura de distribución del poder global cada día más asimétrica y difusa, se trata de un acuerdo que merece ser analizado con cierto detenimiento. El análisis no puede limitarse a un esquema de virtudes y defectos que nos alejaría de una comprensión procesual y dinámica de la propia Agenda. Más bien, a continuación se constatan cuáles son las principales oportunidades que la Agenda ofrece como vías de entrada para hacerla realmente transformadora; para después constatar igualmente cuáles son los principales dilemas ante los que la misma Agenda nos enfrenta.

\section{a) Oportunidades para una Agenda 2030 transformadora}

En comparación con la Agenda de los ODM la nueva Agenda 2030 constituye una agenda mucho más amplia en la medida en que, por un lado, aborda 
muchas más temáticas específicas, y por otra parte, reafirma en numerosas ocasiones la integralidad, multidimensionalidad y universalidad que pretende. Estas afirmaciones explícitas no significan que integralidad, multidimensionalidad y universalidad vayan a alcanzarse solo incorporándolas en la narrativa. Es preciso profundizar hasta establecer de forma clara cuáles son las relaciones entre las diecisiete metas específicas consignadas, lograr aclarar las determinaciones entre las diferentes dimensiones del desarrollo sostenible (económica, ambiental, social y de gobernabilidad) y explotar adecuadamente lo que el término de universalidad significa. Solo a través de este continuo trabajo de interpretación política de la Agenda 2030 esta puede ir ganando mayor coherencia de forma progresiva, dado que en su formulación actual presente serias inconsistencias.

En relación a su carácter integral, la Agenda 2030 afirma que «Los ODS y sus metas son de carácter integrado e indivisible» (United Nations, 2015b: párr. 55) evitando con ello exponer prevalencias o jerarquías entre los 17 objetivos. Deberá ser cada uno de los países los que establezcan sus prioridades para incorporar esas aspiraciones y metas mundiales en sus procesos de planificación, y en sus políticas y estrategias nacionales. Lo que, desde el diagnóstico común y compartido que recoge la Agenda 2030, no deja de ser una limitación. Impuesta sin duda por el carácter intergubernamental de las NNUU y su obligación de respetar la soberanía nacional de cada uno de sus miembros, pero limitación al fin y al cabo si consideramos como cierto que esta Agenda es un verdadero consenso entre todos los países del mundo. Precisamente en aras de dicho acuerdo la Agenda 2030 no ha logrado ir más allá de señalar las aspiraciones comunes para haber sido más prescriptiva de políticas específicas en su formulación.

No sucede igual respecto de la pretendida multidimensionalidad de la Agenda. En varias ocasiones se reafirma el compromiso de lograr un desarrollo sostenible en su multidimensionalidad pero no expresa de qué forma puede lograrse dicho propósito. Al contrario, llama la atención el peso específico del crecimiento económico en relación al conjunto y específicamente en la forma de comprender la dimensión económica del desarrollo. En toda la primera parte de la Agenda 2030 se utiliza una larga fórmula — crecimiento económico sostenido, inclusivo y sostenible - que pretende, de alguna forma, considerar el crecimiento económico con apellidos sociales y ambientales. Dedicándole de forma particular uno de los 17 ODS, el octavo, que recoge la meta del 7\% del PIB de crecimiento anual para los Países Menos Adelantados junto con otras, más imprecisas, como "procurar desvincular el crecimiento económico de la degradación del medio ambiente», "lograr el pleno empleo productivo y garantizar un trabajo decente para todos los hombres y mujeres» $\mathrm{o}$ "poner fin al trabajo infantil en todas sus formas a más tardar en 2025». Nada que cuestione la primacía del crecimiento económico, que constituye implícitamente el principal vector de desarrollo en la visión que traslada la Agenda 2030. 
O no tan implícitamente. Si atendemos a los párrafos de la parte final del texto, aquellos que fueron añadidos en las últimas semanas ${ }^{3}$, en los que los «apellidos» tan bien intencionados como poco cuestionadores del crecimiento desaparecen, para afirmar abiertamente que el crecimiento económico y la verdadera liberalización del comercio constituyen el principal motor del desarrollo (United Nations, 2015b: párr. 66 y ss.) en su forma de proporcionar recursos nacionales. Ha sido una constante en numerosos documentos desde el principio del proceso de construcción de la agenda, en los que el supuesto equilibrio entre las dimensiones económica, ambiental y social aparecía más bien representado como un triángulo escaleno (Martínez, 2013), en el que el lado predominante, por condicionante, ha sido comprender la dimensión económica desde la perspectiva y la condición del crecimiento económico del PIB de los países. En ningún caso se considera como condicionante la reducción de la desigualdad de renta o de emisiones nocivas de tal forma que pudieran justificar una medida diferente del crecimiento económico. Para la esperanza y como oportunidad por la que apostar, la Agenda 2030 dice comprometerse a formular métodos más amplios para medir los avances que complementen al PIB (United Nations, 2015b: párr. 48). Parece muy pertinente elaborar formas de medir el progreso deseado que impidan seguir subordinando las dimensiones del desarrollo a una concepción de la economía aislada y desarraigada de sus anclajes sociales, ambientales y políticos. Una manera adecuada de ir interpretando políticamente la Agenda 2030 puede ser mostrar, explicar y rechazar ese tipo de cálculos económicos desarraigados hoy predominantes, incorporando progresivamente los cuidados, la igualdad y las externalidades ambientales en el pensamiento económico sobre el desarrollo.

Respecto de la tan mencionada universalidad de la Agenda, hay que afirmar que la principal oportunidad que nos proporciona esta, no es tan solo indicar que la Agenda contiene metas y compromisos para todos los países, sino que nos permite entender que no existe ningún país adecuadamente desarrollado, según los parámetros de equilibrio multidimensional de la visión de desarrollo que propugna. La Agenda 2030 constituye así una piedra de toque fundamental para alejarnos de la división del mundo entre países del Norte y países del Sur, que tanto peso ha tenido en el devenir de las teorías del desarrollo. Todos los países tienen enormes desafíos que enfrentar, tanto en su ámbito nacional y territorial como en el ámbito de la corresponsabilidad por los asuntos globales. Las medias nacionales no pueden seguir sirviendo para ocultar que las verdaderas divisiones son de carácter transnacional y tienen más que ver con el acceso al capital que con el territorio que se habita. Esta lectura debe ser integrada en el análisis de las

\footnotetext{
${ }^{3}$ Después de fracasar el intento por parte de los países más poderosos de que el tímido Plan de Acción de la Cumbre de Addis Abeba (Resolución 69/313, aprobado el 27 de julio de 2015) fuera incorporado tal cual en la Agenda 2030.
} 
oportunidades de la Agenda 2030 que poco tendrá que decir si, a partir de ella, no logra comenzar a revertirse el progresivo y alarmante proceso de concentración de riqueza en cada vez menos personas, al tiempo que aumentan los vulnerables y excluidos. Ambos procesos, "caras de una misma moneda», solo pueden enfrentarse desde una lógica que supere las concepciones basadas en la división de países Norte-Sur. Por eso parece fundamental focalizar los esfuerzos sobre las políticas transnacionales y comunes que impactan sobre las personas a lo largo y ancho de todo el mundo, presionando a la baja los estándares laborales, ambientales y de calidad de vida de las mayorías, amenazando el horizonte de un modelo de sociedad basado en los Derechos Humanos.

Finalmente cabe destacar que la Agenda 2030 nos proporciona la oportunidad de observar el mundo de forma algo más compleja que un agregado de países como unidades explicativas del conjunto. Las interdependencias, asimetrías e interconexiones muestran que la única sociedad real es ya una sociedad mundial. Desde esta perspectiva los países deben considerar, a la hora de planificar sus agendas nacionales, que sus responsabilidades con los asuntos globales no finalizan con unas políticas exteriores consecuentes con las responsabilidades compartidas para la provisión de los denominados bienes globales. Es preciso, para atender adecuadamente las relaciones, comprender que las políticas nacionales o domésticas tienen efectos e impactos sobre otros territorios y ciudadanos en el exterior de sus fronteras. Puede pensarse en las políticas de producción y comercialización, en las fiscales, en las ambientales. Incluso en las políticas sociales y su más que evidente efecto de imitación en otros países.

\section{b) Dilemas que enfrentar en la Agenda 2030}

Ante la Agenda 2030 será necesario elegir entre diferentes opciones a pesar de que puedan parecer igual de buenas o malas. Se trata de verdaderos dilemas que enfrentar puesto que apostar por la Agenda 2030 sin más puede conducir a caminos contrarios a los que se pretenden con dicha apuesta. Al contrario, conviene tener presente que, dadas sus ambigüedades e incoherencias, es una agenda en la que hay asumir algunas opciones, en la que hay que interpretar políticamente algunos de sus asuntos fundamentales para superar dichos dilemas. Se trata principalmente de las insuficiencias en materia de los llamados medios de implementación y de la promoción de una Alianza Mundial para el Desarrollo marcada por su carácter voluntario y despolitizado.

En la Agenda 2030 la cuestión de los medios de implementación no ha quedado resuelta de manera satisfactoria. De nuevo, como ya sucedió con la Agenda de los ODM, existe el riesgo de contar con una agenda internacional centrada en las metas sin fuerza prescriptiva para orientar las políticas de los diferentes actores. Durante los años de discusión ha sido una constante la apelación a la ne- 
cesidad de incorporar coherencia y concreción en cuáles serían los medios necesarios para lograr una implementación de los acuerdos. Se han introducido en cada uno de los 17 objetivos una seria de metas — diferenciadas por sus letras correlativas (1.a., 1.b., etc.) de las metas que especifican los propósitos $(1.1,1.2$, etc.) - pero apenas incorpora generalidades, apelaciones a obviedades o nuevos propósitos en materia de acuerdos. En resumen, sirven mejor para asentar determinados procesos en marcha que para cuestionar o reorientar los impactos que en materia de desarrollo tienen dichos procesos. Ni siquiera la inclusión del Objetivo 17 dedicado explícitamente al fortalecimiento de los medios de ejecución y de la Alianza Mundial para el Desarrollo logra incorporar metas con la necesaria precisión, aventurando en cierto modo una repetición de las insuficiencias del antiguo objetivo octavo.

Se delegó gran parte de la discusión sobre los medios de implementación a los debates en torno a la financiación para el desarrollo y a la Cumbre que sobre este proceso se celebró en Addis Abeba en julio de 2015. Allí se cerraron prácticamente todas las esperanzas puestas en que el acuerdo sobre la Agenda 2030 sirviera como motivación para conseguir un «giro de timón» en las principales cuestiones sistémicas detectadas como "cuellos de botella» para completar una agenda transformadora: regulación de mercados financieros; acuerdos sobre política fiscal y regulación y persecución efectiva de las prácticas de elusión y evasión fiscal; reorientación de políticas de promoción comercial hacia prácticas de mayor sostenibilidad y mayores estándares laborales para impulsar la economía real y productiva frente al predominio y el peso de la economía financiera; concreción de la aplicación del principio de responsabilidades compartidas pero diferenciadas en mecanismos de cohesión con compromisos de financiación explícitos y vinculantes en función del mismo; y un impulso al análisis y a la gestión de las deudas externas de los países según criterios y principios de desarrollo. A pesar de los esfuerzos y las propuestas elaboradas por el Grupo de los 77 y apoyadas por las organizaciones de la sociedad civil, el frente de los países con más responsabilidades por su mayor nivel de desarrollo relativo impidió incorporar ninguna de estas cuestiones en el acuerdo final.

Esto obligó a incorporar varios epígrafes, a partir del párrafo 60, sobre medios de implementación de la Agenda 2030 que evidencia las limitaciones del acuerdo, en tanto que solo hace referencias genéricas a las cuestiones que deben ser consideradas como tales, evitando precisar acuerdos que de alguna forma pudieran vincular obligaciones de los países y el resto de actores respecto de las metas acordadas. La Agenda 2030 no ha logrado incorporar ni una sola medida de obligatoriedad al respecto. $\mathrm{Ni}$ siquiera referencias a numerosas obligaciones extraterritoriales de los Estados que en materia de derecho internacional ya constan en protocolos y otros instrumentos jurídicos. Una de las cuestiones más criticadas respecto al contenido final de la Agenda 2030 ha sido su alejamiento del 
enfoque de Derechos Humanos, no solo no adoptando la retórica relativa al Derecho al Desarrollo, que hubiera sido pertinente, sino evitando cualquier tipo de vinculación entre las cuestiones que aborda y las obligaciones de los Estados.

En este sentido, el marco de gobernanza que promueve la Agenda 2030 está marcado por la voluntariedad de los actores, lo que es lo mismo que afirmar que las aportaciones serán arbitrarias y sujetas a cualquier otro tipo de intereses que las circunstancias puedan imponer a los Estados y al resto de actores. En ese marco de arbitrariedad en materia de gobernanza global la Agenda 2030 establece su correlato en la configuración de una Alianza Mundial para el DesarroIlo Sostenible en la que no solo se consolida el denominado sector privado transnacional como un actor relevante, sino que lo hace constituyendo una Alianza de diferentes actores en los que sus diferentes responsabilidades no son tenidas en cuenta. El término multistakeholder es el gran eufemismo de la época puesto que mencionando una obviedad - hay grupos de interesados diferenciables entre sí- consigue invisibilizar lo principal: que cada grupo dispone de capacidades y poder efectivo muy diferentes para hacer valer sus intereses. Optar por una Agenda 2030 sin interpretarla en clave de distribución de poder tan solo supondrá optar por una colección de buenos propósitos que a buen seguro acabarán por frustrarse.

Por eso el principal dilema ante la Agenda 2030 es optar por ella politizándola, es decir, señalando cómo sus metas pueden ser alcanzadas desde una perspectiva política. Apuntando qué políticas, acuerdos, instituciones y actores contribuyen a extender la lógica de desarrollo desde un enfoque de derechos, y señalando al mismo tiempo, cuáles se dirigen en dirección contraria a pesar de las buenas intenciones y sus correspondientes retóricas bienintencionadas. Optar por asumir el papel de multistakeholder sin atender a los diferentes intereses y capacidades, impediría poner el acento necesario en las alarmantes tendencias de privatización que se aprecian en el entorno de NNUU y sus principales programas, con lo que tampoco podríamos advertir de las presiones que la Alianza Mundial para el Desarrollo constituyen para un modelo de sociedad despolitizado, en la que el papel de los Estados sea poco más que proporcionar seguridad e incentivos a los negocios, el de las OSC diseminar y propagar los pretendidos «consensos» sin interpretarlos políticamente y el del sector privado empresarial decidir cuáles son las transiciones y transformaciones adecuadas y posibles. Se trata de una presión constante por modificar en sus postulados esenciales la naturaleza del contrato social que nos ha traído hasta aquí. Esta presión se expresa en la fragilidad de los acuerdos y en cómo las resistencias para incorporar medios de implementación y cambios en las cuestiones sistémicas han sido invencibles. Las fuerzas transnacionales, muchas de ellas conocidas también como fuerzas del mercado, han tenido el poder más efectivo para establecer los límites de la Agenda 2030. 


\section{La agenda como un proceso inacabado}

\section{a) El proceso continúa}

Una idea central en el análisis de la Agenda 2030 y planteada de manera recurrente a lo largo de este texto es la necesidad de concebirla desde una lógica de proceso aun en construcción y, por lo tanto, no acabado. Si bien es cierto que los espacios formales de consulta se concentraron en las partes iniciales del proceso y que ya existe un texto acordado, no es menos cierto que en las siguientes fases de este proceso seguirán existiendo espacios y oportunidades para la participación social. Estos dependerán, en buena medida, de la capacidad que los diferentes actores tengan de abrir y generar oportunidades de participación, lo que, a su vez, dependerá de la naturaleza de lo que se ha denominado estructura de escucha en los diferentes contextos en los que se desarrolle esta agenda.

Parece necesario que en este marco de lógica de proceso los diferentes actores incorporen algunas de las lecciones generadas en el propio proceso de participación de la Agenda 2030 para abrir las oportunidades de participación y orientarla de una manera estratégica, con el objetivo de hacer de ella un elemento sustantivo en el proceso para el logro de cambios estructurales. Será importante para decantar si el punto de partida (o el punto y seguido) de la participación social se sitúa en una lógica de seguimiento e implementación de la agenda (similar a la lógica que la sociedad civil global asumió en el marco de la Agenda del Milenio), o en una lógica de transformación de la propia agenda de manera que aumente su permeabilidad a los debates sobre el desarrollo y las demandas sociales asociadas a estos.

Conviene apuntar que esta reflexión se inscribe en un momento en el que el proceso formal de definición de la Agenda 2030 continúa más allá de la firma del texto de la declaración final. La declaración y los objetivos definidos y acordados en la Asamblea General de NNUU continúan a través de varios procesos, como la Cumbre del Clima COP 21, celebrada en París dos meses después de la Asamblea General de NNUU. Los acuerdos alcanzados en París vienen a completar el texto de la Agenda 2030, tal y como la propia Agenda recoge en su texto, particularmente en el Objetivo de Desarrollo Sostenible (ODS) 13, cuando reconoce

que la Convención Marco de las Naciones Unidas sobre el Cambio Climático es el principal foro intergubernamental internacional para negociar la respuesta mundial al cambio climático (United Nations 2015b).

La Agenda 2030 es explícita respecto a sus expectativas en materia de acuerdos legalmente vinculantes en esta materia, cuando afirma que

en el protocolo u otro instrumento jurídico o conclusión acordada con fuerza legal en el marco de la Convención y aplicable a todas las partes que se apruebe deberán abor- 
darse de manera equilibrada cuestiones como la mitigación, la adaptación, la financiación, el desarrollo y la transferencia de tecnologías, la creación de capacidad y la transparencia de las medidas y el apoyo prestado (United Nations, 2015b: párr. 32).

De igual forma también remite para las cuestiones de biodiversidad a la 13a reunión de la Conferencia de las Partes en el Convenio sobre la Diversidad Biológica, que se celebrará en México.

Junto a ello, otra parte fundamental para el desarrollo de la Agenda 2030 es el proceso de definición de indicadores que permitan medir las metas fijadas, cuestión clave para el seguimiento de la agenda, pero no solo para este propósito. La declaración final mandata al Grupo Interinstitucional y de Expertos sobre los Indicadores de los Objetivos de Desarrollo Sostenible para elaborar el marco de indicadores mundiales, marco que debe ser acordado por la Comisión de Estadística no más tarde de marzo de 2016 que, posteriormente, deberá ser aprobado por el Consejo Económico y Social y la Asamblea General de NNUU (United Nations, 2015b: párr. 75).

Este proceso de definición final de indicadores mundiales, con el que quedaría formalmente cerrada la definición de la Agenda 2030 en términos globales, es de enorme importancia ya que el conjunto de indicadores finalmente propuesto será determinante para continuar concretando el carácter y ambición de la agenda (Adams, 2015). Aunque probablemente revestido de proceso técnico vinculado a la capacidad de medir fenómenos que no son fácilmente mensurables y a partir de fuentes de información no homogéneas, el acuerdo sobre los indicadores parece una continuación de un terreno de disputa que la definición de objetivos y metas no ha terminado de decantar. Es por lo tanto un terreno que no es ajeno al debate teórico sobre el desarrollo y la mirada política resultante de este (Adams, 2015). La apuesta por unos indicadores "de mínimos», la búsqueda de una batería de indicadores desde una lógica de supeditación de unos objetivos a otros o la posible contradicción entre indicadores son algunos de los riesgos fundamentales que supone este proceso, en el que tanto puede producirse un mayor alejamiento del resultado final de la agenda respecto a los resultados de los debates sobre el desarrollo o, a la inversa, un ajuste favorable que otorgue a la agenda una orientación más ambiciosa en términos de desarrollo. Puede suponer, de facto, la incorporación de prevalencias y jerarquías entre objetivos, en contradicción con el equilibrio entre objetivos y dimensiones al que alude la parte más declarativa de la agenda. Por poner solo un ejemplo, la incorporación de indicadores poco ambiciosos sobre desigualdad inspirados por el concepto de clase media global, significa la reconfiguración práctica muy a la baja de un debate que ha estado presente desde el inicio del proceso de construcción de la agenda, a partir de las demandas de grupos y actores apoyados en una amplio consenso doctrinal sobre el papel de las desigualdades como problema central del desarrollo. 
Por lo tanto, una vez pasada la fase de definición de los objetivos y las metas, sigue existiendo un espacio de disputa teórica y política que, lejos de ser entendido como un ejercicio técnico relacionado exclusivamente con la disponibilidad de fuentes, la capacidad de medir, posee una elevada capacidad de seguir modelando la agenda (Adams, 2015).

Tampoco agota la definición del marco de indicadores mundiales el proceso formal de definición de la nueva agenda. La Agenda 2030 «alienta» a los países a formular

lo antes posible respuestas nacionales ambiciosas para la implementación general de la presente Agenda (United Nations, 2015b: párr. 78),

así como a que

realicen exámenes periódicos e inclusivos, liderados e impulsados por países, de los progresos nacionales y subnacionales,

y llama a

aprovechar las contribuciones de los pueblos indígenas, la sociedad civil, el sector privado y otras partes interesadas (United Nations, 2015b: párr. 79),

todo ello dentro del marco de voluntariedad que impregna al conjunto de la Agenda.

Se inicia por lo tanto, de manera paralela al trabajo de definición del marco de indicadores a escala global, un proceso de "aterrizaje» de la Agenda 2030 a los ámbitos nacionales y subnacionales. De igual manera que respecto al ejercicio de definición del marco de indicadores, cómo se produzca el proceso este proceso en clave nacional y subnacional determinará el resultado de la agenda en los diferentes contextos geográficos. Nuevamente es necesario situar el foco, en buena lógica, en el marco de la disputa teórica y política para acercar la agenda a su mayor potencial posible en términos de transformación estructural y hacia la adopción de políticas favorables a un cambio de modelo basado en la idea de sostenibilidad, equidad y justicia global.

Este ejercicio, no obstante, no estará exento de contradicciones y limitaciones, ya que, como se afirmó anteriormente, nos encontramos ante un contexto transnacionalizado en el que desde las lógicas nacionales no es posible abordar las transformaciones necesarias para cumplir con objetivos globales, ni tan siquiera para su logro en clave nacional. Esta aparente contradicción debe ser abordada con perspectiva y en toda su complejidad ya que, de lo contrario, todo ejercicio de implementación de una agenda global y con vocación de universalidad, puede verse sustancialmente desdibujado y alejarse de su propósito. Es im- 
portante por todo ello llevar a cabo una lectura estratégica ya no solo de la parte pretérita, sino también futura, del proceso de construcción de la agenda, sus límites, contradicciones y potencialidades, como base para articular un proceso en el que la Agenda 2030 pueda servir como una herramienta para impulsar los cambios deseados desde la lógica de la equidad, la sostenibilidad y la justicia global.

En definitiva, si el resultado de la agenda ha sido el producto de las condiciones estructurales del proceso y los resultados de este no son acordes a lo que hubiera cabido esperar de ella, ¿Cómo hacer para revertir ese proceso y resignificar la agenda desde la lógica de la doctrina y los debates sobre el desarrollo?, ¿Desde la lógica de la equidad, la sostenibilidad y la justicia global? Es probablemente el gran dilema al que la sociedad internacional, y de manera específica la sociedad civil global, se enfrenta en el marco de la Agenda 2030.

La articulación de una respuesta estratégica tanto en estos primeros cruciales momentos (caracterizados por el debate de los indicadores y la extensión de la agenda en clave nacional y local) como a lo largo de los próximos años de seguimiento de los acuerdos globales y multinivel, se enfrenta a algunos desafíos de enorme calado. Son numerosos desafíos que pueden agruparse fundamentalmente en dos grandes ámbitos: la interpretación de la agenda y, derivada de esta interpretación, la construcción de un discurso y una práctica en el marco de esta agenda.

\section{b) La interpretación de la Agenda}

La interpretación de la Agenda 2030 es una batalla que ya esta en marcha. Desde que se fijaran los ODS en septiembre de 2015 diferentes interpretaciones y narrativas comienzan a difundirse y construirse. Una interpretación bastante extendida y generada en buena medida por la atención mediática inmediatamente posterior a la aprobación de los ODS identifica a la agenda como el acuerdo verdaderamente transformador y la mejor respuesta posible a los problemas del desarrollo. Cierta simplificación y ausencia de mirada a las aristas y a la lógica del poder parece latir en esta narrativa que posee una gran capacidad de construir un relato rápido y lograr una difusión global con cierto rango de oficialidad. Sin embargo, el complejo proceso de construcción y sus límites en el resultado de la agenda debería llevar a evitar lecturas apresuradas y simplificadoras.

Uno de los avances fundamentales que incorpora la Agenda 2030 respecto a la Agenda del Milenio consiste que una parte significativa de su proceso de construcción, a pesar de las limitaciones planteadas, ha sido abierto y accesible a diferentes actores. Ello ha facilitado su conocimiento por parte de un público que, sin ser mayoritario, sí ha sido amplio. 
Como ha tratado de reflejarse en el epígrafe anterior, poder conocer buena parte del proceso e interrelacionar las condiciones en las que este se ha producido y los límites que esto representa en el resultado final es ya un avance en la capacidad de interpretar qué tipo de agenda es la resultante y cuáles son las razones que lo explican.

Al tiempo que ofrecer a numerosos actores una clara información de cuáles son los límites de la agenda y las razones que los explican, el hecho de haber participado de cerca en el proceso de construcción y de analizarla desde una lógica de proceso permite identificar los principales obstáculos de carácter estructural sobre los que la Agenda 2030 no ofrece respuestas adecuadas ni la posibilidad de orientar la acción.

Así pues, detectar y recalcar que la Agenda no incorpora adecuadamente cuestiones centrales para la gobernanza y el desarrollo como la fiscalidad, el comercio, la seguridad humana, etc., y que no incorpora un enfoque basados en los Derechos Humanos es importante para interpretar la agenda, sus límites y sus potencialidades. Conocer las razones que lo explican es, además, estratégico para construir no solo un marco de interpretación, sino para incorporarlo en el constante proceso de reconstrucción y reinterpretación de la agenda, en definitiva, para su resignificación.

Si bien es evidente que cada aproximación a la Agenda 2030 se producirá desde un enfoque teórico diferente y con distintas aspiraciones, motivaciones y fuerzas, parece relevante que este ejercicio de interpretación y análisis de la agenda sea socializado y compartido entre una amplia red de actores y organizaciones. De hecho, numerosos actores en los ámbitos internacionales, nacionales y locales lo están haciendo, algunos como continuación de su trabajo de seguimiento y participación en el proceso de construcción de la Agenda $2030^{4}$ y otros nuevos, generados a partir de la aprobación de la nueva agenda que, lejos de crearse para articular la implementación de la nueva agenda, persiguen la búsqueda de interpretaciones, análisis y reacciones conjuntas entre diferentes actores sociales ${ }^{5}$. En la medida que más y más amplias iniciativas logren articularse, no solo cobrarán mayor fuerza y coherencia desde una lógica integral y multinivel que conecte lo global y lo local. También será más fácil, si esto se

\footnotetext{
${ }^{4}$ Es el caso, entre otras, de la iniciativa Global Policy Watch, formada por las organizaciones Social Watch, Global Policy Forum y la Plataforma 2015 y más. Desde este espacio, se han generado informes de seguimiento y análisis sobre dos diferentes procesos abiertos en torno a la construcción de la Agenda 2030 centrados, precisamente, en el análisis del proceso. Estos análisis pueden consultarse en: https://www.globalpolicywatch.org/

5 Desde una lógica estatal, puede destacarse la iniciativa Futuro en común, formada por organizaciones y movimientos sociales para acabar con la pobreza y las desigualdades, y respetar los límites ambientales del Planeta.
} 
produce, favorecer mejores respuestas y posiciones para la participación futura en el seguimiento de la agenda.

De la misma manera que es necesario realizar un análisis colectivo que permita identificar los principales elementos críticos de esta agenda, no es menos importante que este ejercicio se oriente también hacia las principales potencialidades que la agenda posee. Si, como se ha expresado, la Agenda deja fuera numerosos elementos, especialmente aquellos denominados sistémicos, también es cierto que algunos de los compromisos incorporados, como se planteaba en el epígrafe anterior, sí responden a elementos identificados en los debates sobre el desarrollo como aspectos de gran relevancia para la promoción de cambios estructurales a favor de una mayor sostenibilidad, equidad y justicia global.

De cómo sean incorporados finalmente estos elementos tanto en el marco de indicadores mundial y, en buena medida, de su abordaje en los diálogos nacionales y locales es donde se juegan muchas de las posibilidades de aumentar el carácter transformador de la Agenda 2030.

Este balance de identificación y socialización de los elementos críticos y potenciales dentro de un análisis más amplio acerca de la presencia del «poder estructural» en esta agenda y en relación con otros espacios de gobernanza, será fundamental para la construcción del marco de interpretación generado en torno a la Agenda 2030. Esta cuestión es con probabilidad uno de los elementos más relevantes de cara al futuro y a las posibilidades de la propia agenda.

\section{c) La construcción de la narrativa sobre la nueva agenda y su correlato en la práctica}

\section{Una narrativa basada en la universalidad y en las responsabilidades comunes, pero diferenciadas}

La pugna por el marco de referencia sobre el que interpretar la Agenda 2030 es estratégica para construir una narrativa que favorezca la capacidad transformadora de la agenda. Dicho de otra manera, se constituye en un potencial elemento de construcción de la agenda y por lo tanto forma parte de la agenda misma. De ahí la importancia de cómo y por parte de quién se construya dicha narrativa no solo para explicarla y lograr una comprensión amplia y generalizada, sino también para contribuir a abrir los límites de la propia agenda. $\mathrm{Si}$, como se ha planteado, no habrá una, sino muchas narrativas, y el espacio discursivo continuará siendo un terreno de disputa, en la medida que más sólido, agudo y compartido sea el análisis de la agenda más posibilidades habrá de construir un marco de interpretación que permita abrir la agenda.

Una piedra angular en la construcción de la narrativa sobre la nueva agenda internacional de desarrollo es la incorporación del principio de universalidad. Este 
supone el reconocimiento explícito de que los problemas del desarrollo no son problemas del Sur global, sino que son problemas resultado del orden internacional existente y del modelo de desarrollo en su conjunto. En coherencia con este principio, un modelo sostenible, equitativo y con vocación de justicia global demanda cambios estructurales que interpelan al conjunto de los actores. Es pues el propio modelo de desarrollo de todos los países el que es necesario revisar para dirigirnos hacia un modelo, tanto global como en su manifestación local, sostenible, equitativo y justo. Es necesario, no obstante, abordar el principio de universalidad en relación con otro de los principios planteados en la agenda, el de las «responsabilidades comunes, pero diferenciadas» (United Nations, 2015b: párr. 12). No abordar el principio de universalidad desde una óptica diferenciadora en relación a las responsabilidades podría, además de no atender a la realidad de la transnacionalización del poder estructural, «inutilizar» el principio de universalidad y profundizar con ello en la brecha Norte-Sur y acentuar las asimetrías globales.

\section{Una narrativa integral}

En clara relación con la ruptura que supone el principio de universalidad respecto a la idea del desarrollo como un proceso lineal y, derivado de ello, con el hecho de que los diferentes países y actores deban revisar su propio modelo de desarrollo, cobra fuerza la idea de la integralidad en el análisis y el abordaje de los problemas del desarrollo.

Se trata de una idea que aunque parece cada vez más aceptada y asumida, enfrenta enormes resistencias que dificultan el paso desde el mundo de las ideas a la práctica, tanto en el plano político como en el de la actuación de las organizaciones sociales. Es la dificultad de trascender la práctica política y la cultura de numerosas organizaciones que tienden a concentrar en la política de cooperación buena parte de los esfuerzos políticos y sociales para la puesta en marcha de procesos de desarrollo internacional. Nuevamente, el carácter multidimensional que inspira esta agenda constituye una oportunidad para romper con esa idea de la compartimentalización de políticas que, de facto, ha naturalizado una lógica en la que la existencia de un modelo incoherente, con políticas incoherentes ha sido sistemáticamente relativizado por la existencia de amplios espacios de participación e intervención en la política de cooperación (Plataforma 2015 y más, 2011b). La promoción de la coherencia de politicas para el desarrollo como un mandato político y como un espacio de intervención de las organizaciones sociales, más allá de su reconocimiento como un análisis sugerente pero de carácter normativo, es un elemento clave para lograr esta transformación. Así pues, aquí radica una de las oportunidades y de los ejes potenciales para hacer de esta una agenda más amplia y sistémica, al suponer un espacio para la promoción de la coherencia de políticas situando la equidad, la sostenibilidad y la justicia global en el centro no solo del debate, sino también de la práctica política y de la actuación de las organizaciones sociales (Plataforma 2015 y más, 2015). 
Es necesario apuntar que esto implica un paso fundamental no solo en el marco de implementación de la agenda, sino también en la tarea de la interpretación y la construcción de la narrativa. A diferencia de lo que ocurriera con los ODM, no puede darse un proceso en el que sea el sector de la cooperación el que interpreta y traslada la Agenda al resto de la sociedad (como ya ha pasado en buena medida en el proceso de construcción de la nueva Agenda 2030). Una adecuada interpretación y la consiguiente construcción de una narrativa con capacidad de ampliar los límites de la Agenda dependen directamente de la participación de los diferentes colectivos y actores sociales. En este sentido, si una de las potencialidades de esta agenda es su llamada a superar la idea de la sectorialización para afrontar la construcción de un análisis integral, pareciera que solo desde procesos de análisis y construcción planteados desde una lógica integral podrá abordarse con garantías un ejercicio de esta naturaleza.

Así pues, es a través de un diálogo democrático y transversal, de carácter social y político, y en el marco de los debates sobre el desarrollo como mejor puede construirse la narrativa sobre la nueva agenda que, al tiempo que refavorezca su socialización, sea capaz de transformarla y ampliarla.

Parece consecuente, para avanzar en ese camino, desechar la idea de aproximarse a la Agenda a partir de una única estructura organizada y legitimada para ello. Dados los ámbitos en los que se que se concreta esta agenda y teniendo presente los ámbitos de poder estructural en los que esta carece de fuerza, pareciera más estratégico desarrollar un trabajo en red —en el interior de las cuales bien puede haber alianzas muy sólidas - capaz de articular diferentes visiones, diferentes estrategias y con suficiente versatilidad y audacia para identificar los procesos de desplazamiento del poder estructural.

Ello bien podría servir también para evitar el elevado riesgo de que la articulación de las diferentes miradas y respuestas generadas desde espacios de sociedad civil y generación de pensamiento, reproduzcan a escala nacional lo que en el proceso de construcción de la Agenda 2030 se ha configurado como un partenariado global — construido sobre la idea de ausencia de responsabilidades, y por lo tanto despolitizado- como única respuesta a la gobernanza de los problemas del desarrollo.

\section{Una narrativa multinivel y democrática}

Se ha planteado a lo largo de este texto la importancia de atender a la naturaleza transnacional del poder para entender los límites de la nueva Agenda internacional de desarrollo. Para entender mejor el proceso de difusión del poder es preciso contemplar también otras lógicas que forman parte del proceso de transnacionalización y que también implican una redefinición del poder y son sustanciales para entender la configuración de los procesos de desarrollo. En un contexto de interdependencia creciente resultado del proceso 
globalizador es preciso llamar la atención acerca de los fenómenos de desterritorialización y reanclaje territorial, que otorgan a los actores locales una naturaleza cada vez más internacional y diluyen las fronteras entre lo local y lo global (Keating, 2001; Martínez y Sanahuja, 2012; Ugalde, 2006; Millán, 2013).

Son fenómenos cruciales que remiten a una lógica multinivel en la definición del poder estructural (Martínez y Sanahuja, 2012; Martínez, 2015), y por lo tanto para entender tanto las fuerzas que actúan en la configuración de los problemas, en su manifestación y, como resultado, aumentar la capacidad para identificar y articular mejores respuestas a los problemas del desarrollo.

De este modo, la Agenda 2030 tendrá mayores posibilidades de éxito en la medida que contribuya a favorecer una gobernanza multinivel y democrática. Por ello, a diferencia de lo que ocurriera con los ODM no puede verse como una agenda «internacional» sin apenas implicaciones para los actores locales. Por el contrario, el necesario para la ampliación y del desarrollo de la agenda desde una lógica multinivel y democrática que tanto el marco de interpretación como la construcción de la narrativa se construyan desde una lógica interméstica en la que lo local y global constituyen ámbitos interdependientes de una misma realidad «transnacionalizada».

Así pues, es necesario que en el marco de interpretación y en la construcción de la narrativa estén presentes los actores subestatales y la sociedad civil articulada localmente. Lo es porque en buena medida estos serán actores protagonistas en su implementación. Pero lo es, especialmente, porque del hecho de que estos sean parte central de ese proceso de resignificación dependerá, nuevamente, la capacidad de ampliar los límites de la agenda a favor de una lógica multinivel y democrática.

\section{Reflexiones finales}

El año 2015 representaba un hito importante para la Agenda internacional y el debate sobre el desarrollo. Era el año en el que se cumplía el plazo para alcanzar los ODM. El balance de esta agenda, su evidente incumplimiento a pesar de su relativa capacidad de atracción, ha generado numerosas lecciones para el proceso de continuación de la Agenda internacional de desarrollo a través de la Agenda 2030.

Una de las lecciones más importantes que se pueden extraer y que determinará el futuro de la nueva agenda es que la agenda, lejos de ser un marco dado y definido, es un resultado de la economía política internacional del desarrollo en un marco de creciente transnacionalización del poder estructural. Es por lo tanto la utilización de la agenda, su evolución y su interacción con otras es- 
feras de poder estructural lo que determinará su capacidad para contribuir a la construcción de un mundo más justo, equitativo y sostenible. Esta utilización no puede comprenderse como una adopción acrítica de la misma, ni circunscribirse al periodo de implementación que deberá comenzar a primeros de enero de 2016. La agenda puede ser un consenso paralizante y quedarse pequeña ante el dinamismo de la realidad y la constante transformación y desplazamiento del poder. Algo similar sucedió con los ODM que finalmente constituyó una referencia de carácter doctrinal o normativa para las políticas que una verdadera guía para la práctica de la misma.

La participación y la transformación de la propia Agenda al dinamismo de la realidad y su adecuación a los desplazamientos del poder serán fundamentales para que la Agenda supere esa lógica estática. Y no parte de buen lugar para ello, debido al empeńo institucional muy extendido, de presentar la misma más como un acuerdo cerrado y completo que como una serie de principios a los que aún les resta concretar medios fundamentales de implementación, enfoques amplios de derechos humanos y abordar cuestiones de carácter sistémico nucleares para las transformaciones pretendidas.

El papel de la sociedad global y su capacidad para ser parte activa en la transformación del poder estructural será un elemento crucial para el futuro de la agenda. En concreto, será fundamental la capacidad e influencia que esta tenga en la construcción de un marco de interpretación y una narrativa capaces de ampliar los límites de la agenda y de hacerla interactuar con aquellas otras esferas del poder estructural en las que se definen las cuestiones más determinantes para la configuración del desarrollo. No puede ignorarse la enorme tarea que exige a numerosas organizaciones de esta sociedad civil global transitar hacia un contexto en el que su papel fundamental no reside ya en la implementación de una agenda estática, sino en la interpretación y la construcción de la Agenda 2030 para hacer de ella una realidad dinámica y adecuada a las transformaciones que un mundo sostenible, equitativo y justo exigen.

\section{Bibliografía}

ADAMS, Barbara (2015): «Indicadores y datos de los ODS: ¿Quién recauda? ¿Quién informa? ¿Quién se beneficia?», Global Policy Watch, 9. En: http://www.2015ymas.org/ documentos_ver.asp?id=263

ADAMS, Barbara y MARTENS, Jens (2015): «Fit for Whose Purpose?», Global Policy Watch, 8. En: https://www.globalpolicywatch.org/wp-content/uploads/2015/07/ GPW8_2015_07_27.pdf

ALONSO, José Antonio (2006): "Cambios en la doctrina del desarrollo: el legado de Sen", en MARTÍNEZ, Vincent y PARÍS, Sonia (eds.), Amartya K. Sen y la globalización, Castellón, Universitat Jaume I. 
ALONSO, José Antonio (2013): «La agenda post-2015 y los países de renta media», en ALONSO, José Antonio (dir.), Compromiso global por un desarrollo incluyente y sostenible. Consideraciones sobre la agenda post-2015, Documentos de Trabajo Cooperación Española, 94-110.

BISSIO, Roberto (2011): «La octava meta: un objetivo pendiente», en MARTÍNEZ OSÉS, Pablo J. (coord.), Las politicas globales importan. Octavo informe anual de la Plataforma 2015 y más, Madrid, IEPALA Editorial, 37-43.

BUSTELO, Pablo (1998): Teorías contemporáneas del desarrollo económico, Madrid, Síntesis.

CHERU, Fantu, y BRADFORD, Colin Jr. (2005): The Millennium Development Goals: raising the resources to tackle world poverty, London, Zed Books.

CORNAGO, Noé (1997): «Desarrollo, subdesarrollo y postdesarrollo: un análisis crítico del debate contemporáneo», en Cursos de Derecho Internacional de Vitoria-Gasteiz, Bilbao, Tecnos/UPV, 39-88.

COX, Robert W. (1996) "Take six eggs": theory, finance and the real economy in the work of Susan Strange», en COX, Robert with SINCLAIR, Timothy J., Approaches to World Order, Cambridge University Press.

DELGADO, Gian Carlo (ed.) (2014): Buena vida, buen vivir: imaginarios alternativos para el bien común de la humanidad, México D.F., Universidad Nacional Autónoma de México (UNAM).

FERNÁNDEZ, Gonzalo, PIRIS, Silvia y RAMIRO, Pedro (2013): Cooperación internacional y Movimientos sociales emancipadores: bases para un encuentro necesario, Bilbao, Universidad del País Vasco-Euskal Herriko Unibertsitatea.

GILL, Stephen (1995): «Globalisation, market civilisation, and disciplinary neoliberalism", Millennium-Journal of International Studies, 24 (3): 399-423.

GILL, Stephen (2008): Power and Resistance in the New World Order: Fully Revised and Updated, London, Palgrave Macmillan.

KEATING, Michael (2001): «Regiones y asuntos internacionales: motivos, oportunidades y estrategia», en ALDECOA, Francisco y KEATING, Michael (eds.), Paradiplomacia: las relaciones internacionales de las regiones, Madrid, Marcial Pons.

LAWTON, Thomas C., ROSENAU, James N. y VERDUN, Amy (2000): Strange power: Shaping the parameters of international relations and international political economy. Aldershot/Burlington, Ashgate.

MARTÍNEZ, Ignacio (2013): «Visiones del desarrollo en la agenda post-2015», en MARTÍNEZ OSÉS, Pablo J. (ed), La agenda de desarrollo post-2015: ¿más de lo mismo $o$ el principio de la transición? Dossier EsF n. ${ }^{\circ 11}$, Madrid, Economistas sin Fronteras, $12-17$.

MARTÍNEZ, Ignacio (2015): «¿Es posible una gobernanza basada en los derechos globales?», en MARTÍNEZ, Ignacio y GIL, Maria Luisa (coords.), $Y$ después de 2015, ¿qué hacemos? XII Informe anual de la Plataforma 2015 y más, Madrid, Editorial 2015 y más, 95-105.

MARTÍNEZ, Ignacio y SANAHUJA, José Antonio (2012): «La cooperación descentralizada espańola y la eficacia de la ayuda: los desafíos de la complementariedad y la división del trabajo», en MARTÍNEZ, Ignacio y SANAHUJA, José Antonio (coords.), Eficacia de la ayuda y división del trabajo: retos para la cooperación descentralizada española, Madrid, Ceipaz-ICEI, 11-34.

MARTÍNEZ OSÉS Osés, Pablo J. (2005): Objetivos del milenio: ¿se puede acabar con la pobreza?, Madrid, PPC. 
MARTÍNEZ OSÉS, Pablo J. (2015): «Aprendizajes de los ODM: hacia una hoja de ruta post-ODM», en MARTÍNEZ, Ignacio y GIL, Maria Luisa (coords.), $Y$ después de 2015, ¿qué hacemos? XII Informe anual de la Plataforma 2015 y más, Madrid, Editorial 2015 y más, 41-48.

MILLÁN, Natalia (2013): Transnacionalización del desarrollo y coherencia de politicas: un análisis de los casos de España y Suecia, Tesis Doctoral, Universidad Complutense de Madrid.

OECD-CAD (2014): DAC High Level Meeting. Final Communiqué. 16 december 2014, OCDE-CAD.

PINGEOT, Lou (2014): La influencia empresarial en el proceso post-2015, Madrid, Editorial 2015 y más.

PLATAFORMA 2015 Y MÁS (2004): La palabra empeñada: los objetivos 2015 y la lucha contra la pobreza: segundo Informe Anual de la Plataforma 2015 y Más, Madrid, CYAN,

PLATAFORMA 2015 Y MÁS (2005): Alianzas contra la pobreza: la acción de las ONGD para alcanzar los objetivos del milenio. Tercer informe anual de la Plataforma 2015 y más, Madrid, Los Libros de la Catarata.

PLATAFORMA 2015 Y MÁS (2006): Los objetivos del Milenio: movilización social y cambio de politicas. Cuarto informe anual de la plataforma 2015 y más, Madrid, Los Libros de la Catarata.

PLATAFORMA 2015 Y MÁS (2008a): El Derecho a no ser Pobre. Situación de la lucha contra la desigualdad en tiempo de crisis 2008. Sexto informe anual de la Plataforma 2015 y más, Madrid, IEPALA Editorial.

PLATAFORMA 2015 Y MÁS (2008b): El perfil social del desarrollo. Quinto informe anual de la Plataforma 2015 y más, Madrid, Icaria.

PLATAFORMA 2015 Y MÁS (2009): Para salir de la crisis primero la gente. Situación y perspectivas de la lucha contra la pobreza y la desigualdad en tiempos de crisis 2009. Séptimo informe anual de la Plataforma 2015 y más, Madrid, IEPALA Editorial.

PLATAFORMA 2015 Y MÁS (2011a): Las politicas globales importan. Octavo informe anual de la Plataforma 2015 y más, Madrid, IEPALA Editorial.

PLATAFORMA 2015 Y MÁS (2011b): «Renovando nuestro papel hacia la transformación social», en MARTÍNEZ, Ignacio (coord.), Renovando el papel de las ONGD, Madrid, Editorial 2015 y más, 71-89.

PLATAFORMA 2015 Y MÁS (2012): Politicas coherentes para una ciudadanía global. IX Informe anual de la Plataforma 2015 y más, Madrid, Editorial 2015 y más.

PLATAFORMA 2015 Y MÁS (2013): Otro mundo está en marcha. X Informe anual de la Plataforma 2015 y más, Madrid, Editorial 2015 y más.

PLATAFORMA 2015 Y MÁS (2014): Hacia 2015: visiones del desarrollo en disputa. XI Informe anual de la Plataforma 2015 y más, Madrid, Editorial 2015 y más.

PLATAFORMA 2015 Y MÁS (2015): Y después de 2015, ¿qué hacemos? XII Informe anual de la Plataforma 2015 y más, Madrid, Editorial 2015 y más.

SANAHUJA, José Antonio (2005): «Seguridad, desarrollo y lucha contra la pobreza tras el 11-S: los Objetivos del Milenio y la «securitización» de la ayuda», Documentación social 136, 25-41.

SANAHUJA, José Antonio (2007): “¿Más y mejor ayuda? La Declaración de París y las tendencias en la cooperación al desarrollo», en MESA, Manuela (coord.), Guerra y conflictos en el siglo XXI: Tendencias globales. Anuario CEIPAZ 2008, Madrid, Ceipaz. 
SANAHUJA, José Antonio (2013): «Las nuevas geografías de la pobreza y la desigualdad y las metas de desarrollo global post-2015", enMESA, Manuela (coord.), El reto de la democracia en un mundo en cambio: respuestas politicas y sociales. Anuario CEIPAZ 2013-2014, Madrid, Ceipaz, 61-100.

SEN, Amartya (2000): Desarrollo y Libertad, Barcelona, Planeta.

STRANGE, Susan (1994): States and markets, London-New York, Continuum.

STRANGE, Susan (2001): La retirada del Estado: la difusión del poder en la economía mundial, Barcelona, Intermón Oxfam Editorial.

TEZANOS, Sergio (2011): «Más allá de 2015: Objetivos de Desarrollo del Milenio y desafíos para la nueva agenda internacional de desarrollo", Sistema: Revista de ciencias sociales 220-221: 33-58.

UGALDE, Alexander (2006): «La acción exterior de los Gobiernos No Centrales en la Unión Europea Ampliada», en Cursos de Derecho Internacional y Relaciones Internacionales de Vitoria-Gasteiz 2005, Bilbao, Universidad del País Vasco, 268-343.

UNCETA, Koldo (2009): «Desarrollo, subdesarrollo, maldesarrollo y postdesarrollo: una mirada transdisciplinar sobre el debate y sus implicaciones», Carta Latinoamericana. Contribuciones en desarrollo y sociedad en América Latina, 7, 1-34.

UNCETA, Koldo (2014): Desarrollo, postcrecimiento y buen vivir: debates e interrogantes, Quito, Ediciones Abya-Yala.

UNITED NATIONS (2015a): «Sustainable Development Knowledge Platform», recurso electrónico.

UNITED NATIONS (2015b): Transforming Our World: The 2030 Agenda for Sustainable Development, A/RES/70/1, United Nations.

UN-NGSL (2013): Advancing Regional Recommendations on the Post-2015 Development Agenda, United Nations.

UN-SG (2014): Synthesis Report of the Secretary-General on the Post-2015 Agenda, United Nations.

VANDEMOORTELE, Jan (2002): Are the MDGs feasible?, New York, United Nations Development Programme. 